\title{
Ignorance is not an excuse - Irresponsible neurocognitive test use highlights the need for appropriate training
}

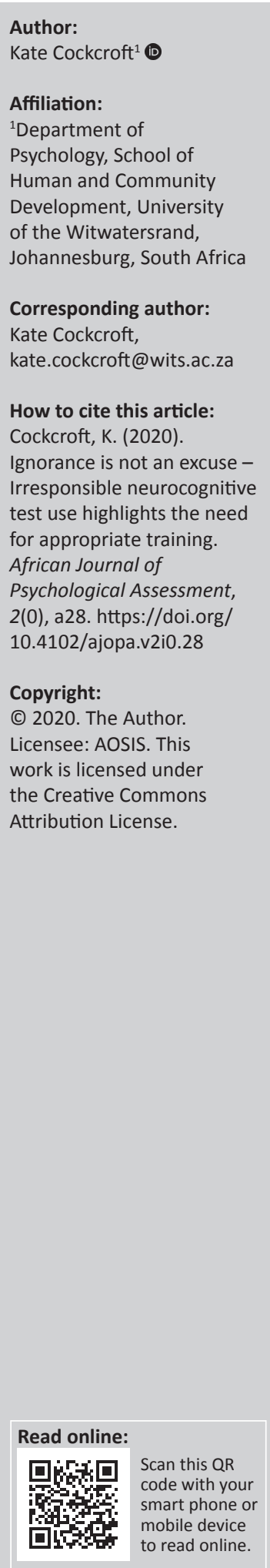

Neurocognitive assessment is a complex endeavour. Its focus is traditionally on brainbehaviour relationships and how injury or disease may impact the cognitive, emotional, physical, sensorimotor and adaptive abilities of the individual (Vanderploeg, 2000). The main aim of such an assessment is typically the identification of impairment for the purposes of rehabilitation, therapy and treatment, and research into neurocognitive assessment is based on the intention to advance this aim. In Africa, possibly the greatest challenge for those conducting neurocognitive assessment and related research is the linguistic, cultural, educational and socioeconomic diversity and complexity of our populations, and how to ethically and fairly evaluate normative and non-normative behaviour in such contexts. Increasingly, even in Western, educated, industrialised, rich and developed ([WEIRD]; Heinrich, Heine, \& Norenzayan, 2010) contexts, the identification of neurocognitive impairment is somewhat nebulous and may be operationalised in different ways by different practitioners and researchers. Researchers and practitioners emphasise that neurocognitive test scores should always be evaluated within the broader context of a person's sociocultural, educational, psychological, linguistic and occupational history and are aware that interpretation of test results extends beyond the neurocognitive evaluation of the individual (Lezak, Howieson, \& Loring, 2004). Similarly, researchers and practitioners understand that neurocognitive tests need to be examined critically in terms of their validity as measures of neurocognition for the person with whom they are being used.

Testing (for either diagnostic or research purposes), without a critical consideration of the instruments used and the individual they are used with, will result in unethical, culturally insensitive use, and interpretation of, neurocognitive measures. Africa and its people have long been the recipients of such uncritical testing, and one would anticipate that there would be greater sensitivity in the use of such tests by now (Laher \& Cockcroft 2014). However, the consequences of such practice have been felt recently. Nieuwoudt, Dickie, Coetsee, Engelbrecht and Terblanche (2019, p. 1) published an article in the journal Aging, Neuropsychology, and Cognition (since retracted by the journal), in which they used the Montreal Cognitive Assessment (MoCA), a screening test for cognitive impairment, with a South African sample in order to argue that coloured ${ }^{1}$ women had 'low cognitive function'. Despite evidence that the psychometric properties of the MoCA vary across different countries and demographic variables, with performance highly sensitive to age and level of education (Ashworth et al., 2014), Nieuwoudt et al. (2019) used this instrument to make flawed, racist and reckless generalisations. See Hendricks, Kramer and Ratele (2019) for a detailed critique of this research.

Another article (Asongu \& Kodila-Tedika, 2019, p. 1) argued that African countries whose citizens have higher intellectual ability were 'more likely to experience lower levels of slave exports ... probably due to comparatively better capacities to organize, co-operate, oversee and confront slave traders'. In this article, intelligence is measured by means of the historic intelligence quotient (IQ), defined as the 'national average intelligence quotients of populations, including estimates of indigenous populations for the colonized countries' (Asongu \& Kodila-Tedika, 2019, p. 4). The questionable analyses in this paper aside, the very assumption on which the measurement and use of IQ are based ignores a long, shameful history of the abuse of IQ tests to exclude and control marginalised communities and is blind to the issues of construct validity and bias. It fails to consider acculturation variables, such as language usage, test-wiseness (test-taking skill, motivation and perceptions of test face validity), socio-economic status (SES), home and school environments and level and quality of education, which are widely known to be key factors in considering a person's IQ test performance (Cockcroft, Alloway, Copello, \& Milligan, 2015; Shuttleworth-Edwards et al., 2004).

1.'Coloured' refers to the official South African government racial classification, as used by Nieuwoudt, Dickie, Coetsee, Engelbrecht and Terblanche $(2019$, p. 1). 
Such unethical use, and interpretation, of neurocognitive tests and their latent constructs stems partly from the fact that the people using these are not trained in them (researchers from a department of sport science in the instance of the first article and from a business school in the second). Practitioners and researchers are morally culpable if they ignore the limitations of using and interpreting neurocognitive data obtained from tests used in Africa, but which were standardised in global North contexts (Watts \& ShuttleworthEdwards, 2016).

It is our role, as practitioners and researchers in Africa, not to allow such problematic research and to make a positive contribution to the body of knowledge through sound and ethical practices. Ensuring such practice is difficult given that many tests of neurocognition are openly available. Training in psychometrics and the appropriate use of psychological assessment instruments is generally only included in postgraduate programmes in psychology. However, many other disciplines undertake research that employs measurement of neurocognitive abilities, whether in the form of self-report questionnaires, scales or standardised assessments. The advent of digital neuropsychology means that such tests are increasingly available in open-source and digital formats, leading to a high probability of misuse. If we are serious about ethical and responsible research that is sensitive to our context and our people, all research methods training should incorporate an introduction to psychometric principles and practices so that researchers can use open-access tests ethically. Such introductory courses can, for example, demonstrate how tests of neurocognition hold cross-cultural biases, and that these are most evident (but not exclusively) in tasks that tap crystallised, long-term learning, irrespective of whether the format is verbal or non-verbal. Certain measures tapping fluid processing (such as processing speed) also appear to hold cultural and experiential biases (Cockcroft et al., 2015; Shuttleworth-Edwards et al., 2004). Training that emphasises the challenges in measuring and identifying individual differences in neurocognition will go a long way towards ensuring sensitive and responsible assessment, as well as rigorous research that strengthens the credibility of the field.

\section{References}

Asongu, S., \& Kodila-Tedika, O. (2019). Intelligence and slave exports from Africa. Journal of Interdisciplinary Economics, 31, 1-15. https://doi.org/10.1177/ 0260107919829963

Ashworth, B., Dilks, L., Hutchinson, K., Hayes, S., Moore, M., Orozoco, A., ... Barnett, O. (2014). A pilot study of age and education norms for the Montreal Cognitive Assessment. Archives of Clinical Neuropsychology, 29(6), 527-528. https://doi. org/10.1093/arclin/acu038.67

Cockcroft, K., Alloway, T., Copello, E., \& Milligan, R. (2015). A cross-cultural comparison between South African and British students on the Wechsler Adult Intelligence Scales Third Edition (WAIS-III). Frontiers in Psychology, 6, 1-11. https://doi. org/10.3389/fpsyg.2015.00297

Hendricks, L., Kramer, S., \& Ratele, K. (2019). Research shouldn't be a dirty thought, but race is a problematic construct. South African Journal of Psychology, 49(3), 308-311. https://doi.org/10.1177/0081246319852548

Heinrich, J., Heine, S.J., \& Norenzayan, A. (2010). The weirdest people in the world? Behavioral and Brain Sciences, 33(2-3), 61-83. https://doi.org/10.1017/ S0140525X0999152X

Laher, S., \& Cockcroft, K. (2014). Psychological assessment in post-apartheid South Africa: The way forward. South African Journal of Psychology, 44(3), 303-314. https://doi.org/10.1177/0081246314533634

Lezak, M.D., Howieson, D.B., \& Loring, D.W. (2004). Neuropsychological assessment (4th edn.). New York, NY: Oxford University Press.

Nieuwoudt, S., Dickie, K.E., Coetsee, C., Engelbrecht, L., \& Terblanche, E. (2019). RETRACTED ARTICLE: Age-and education-related effects on cognitive functioning in Colored South African women. Aging, Neuropsychology, and Cognition, 27(3), 1-17. https://doi.org/10.1080/13825585.2019.1598538

Shuttleworth-Edwards, A.B., Kemp, R.D., Rust, A.L., Muirhead, J.G.L., Hartman, N.P., \& Radloff, S.E. (2004). Cross-cultural effects on IQ test performance: A review and preliminary normative indications on WAIS-III test performance. Journal of Clinica and Experimental Neuropsychology, 26(7), 903-920. https://doi.org/10.1080/ 13803390490510824

Vanderploeg, R. (2000). Clinician's Guide to Neuropsychological Assessment (2nd edn.). Mahwah, NJ: Lawrence Erlbaum Associates.

Watts, A.D., \& Shuttleworth-Edwards, A.B. (2016). Neuropsychology in South Africa: Confronting the challenges of specialist practice in a culturally diverse developing country. The Clinical Neuropsychologist, 30(8), 1-20. https://doi.org/10.1080/ 13854046.2016.1212098 